\title{
5 \\ Challenges of Institutional Leadership: Reluctance in the Australia Council
}

Policy development is a site where creative leadership can translate into institutional leadership-as is the case with artists from non-English speaking backgrounds (NESB) who have participated in the Australia Council Multicultural Advisory Committee (ACMAC) and as advocates for the arts in a multicultural Australia. In this chapter, I articulate how the creative leadership capacities of NESB artists can inform institutional leadership through participation in governance and policy development. Both staff in institutions and art practitioner peers can demonstrate institutional leadership for multicultural arts practices, and this is ideally shown when the strategic aims of the agency and those of multicultural arts policy align. However, NESB artists often face challenges and contradictions when they become affiliated with the apparatus of a government arts agency, in this case, the Australia Council. In particular, I explore the empirical data that underpin the central role of ACMAC in formulating the Arts for a Multicultural Australia 1996 and the Arts in a Multicultural Australia (AMA) 2000 and 2006 policies, and the implications for sector leadership caused by ACMAC's dissolution in 2007.

A multicultural arts milieu is most likely to flourish when there is active engagement and leadership by institutional funding bodies. This engagement includes options of governance, the ability for internal champions to progress change, the ways external expertise is accommodated 
on a regular basis and how advocates gain experience. Institutional leadership also refers to positional leadership and, in the context of the Australia Council, applies to the experience of two ACMAC chairs and several members who describe their combative experiences of governance. Relational and distributed styles of leadership were often displayed by ACMAC to manage these experiences, while transactional styles of leadership were more likely to be displayed by the executive. The Cultural Engagement Framework (CEF), which is the current mechanism adopted by the Australia Council, is promoted as delivering greater internal and external accountability across all diversity areas and, therefore, bears close critique in terms of delivering to the arts in a multicultural Australia. These institutional issues of leadership are explored through the friction arising from governance, the use of expertise to garner trust and the crucial role of networks to produce traction.

\section{Adapting Friction into Governance}

Consultative groups provide expert advice to confirm or adjust institutional aims and strategies. The political pressures that often underpin the need for a policy response can generate internal debates regarding strategy implementation and, in so doing, highlight the potential for friction in governance. One of the remits of diversity advisory committees such as ACMAC is to identify where adjustments (of whatever scale) need to be made. In hierarchical, rule-bound institutions, such adjustments (a result of friction in the first place) may also generate friction in response. The internal institutional development of a policy that, in the end, appears as a neat summation of intentions and actions often comes about through 'robust debate' and compromise. It can be a 'gritty' experience because policy development tests the boundaries of influence and power between advisers and the institution. As Tsing $(2005,6)$ points out 'difference can disrupt, causing everyday malfunctions as well as unexpected cataclysms. Friction refuses the lie that [global] power operates as a well-oiled machine'.

Policy statements in the arts are often presented to the public as the result of a smooth process of identifying issues and addressing gaps. However, internal processes are more likely to be charged with difficult debates. Challenges to the image of their smoothly running institution mean that institutional leaders may 'open the door' to discussing the challenge in question-in the case of the Australia Council, cultural diversity in the 
arts - or they may push back as a form of 'profound resistance' (Blonski 1994, 206). The engagement by those in Australia Council leadership roles towards issues of cultural difference in the arts appear to have generated a significant moment in each decade of its existence. These moments include:

- the establishment of an advisory committee in 1975

- the first multicultural policy proposals adopted by council in 1985

- ACMAC-led national discourse about multiculturalism in 1994

- significant resources invested across discourse, artistic and market development in 2000 .

Each of these productive phases resulted from creative and institutional frictions that required energy to (re-)establish the AMA agenda and also generate the subsequent momentum for its ongoing delivery. This history suggests an institutional pattern that begins with disregard, prompts criticism from practitioners and subsequently catalyses the institution into developing a response and, sometimes, a process for change.

\section{The Mirage of a Legacy}

The chairs of ACMAC all held positional leadership roles. As government appointees, one of their main remits was to steer the issues raised by their committee to be approved at the level of the Australia Council Board, the highest level of internal governance and decision-making (a schematic organisational chart of this period is at Appendix C). ACMAC was usually chaired by the chair of the Community Cultural Development Board (CCDB). This was the case for two research participants: actor Lex Marinos and comedy scriptwriter Deborah Klika, whose stories provide rare insight into governance roles at the Australia Council. As government appointees, they can be described as 'political' chairs because this is 'the world of some art boards. They are a play between heroes, politics, power and personal crusade, where being visible and speaking out oscillate with invisibility and discretion' (Rentschler 2015, 106). Rentschler depicts the tension in arts governance leadership between public profile, government expectations and attending to a constituency. ACMAC chairs had to juggle these roles with other members of the Australia Council governing board, other members of ACMAC, and the complex and changing constituency in the 'multicultural arts' sector-and do so in relation to the government of the day. 
Marinos established his creative leadership as an actor and multicultural advocate. This role merged with his institutional leadership during his roles at the Australia Council as deputy chair and chair, respectively, of the CCDB and ACMAC. The AMA policy area is also a site in which the creative leadership of NESB artists can merge with institutional leadership. In such contexts, their creative leadership is stimulated by social and political engagements that may inform their practice as well as develop advocacy capabilities. This process can also move them into the spotlight as candidates for institutional leaders in a governance role.

For example, Marinos's appointment as chair of ACMAC coincided with his position as director of NSW's Carnivale Multicultural Arts Festival. He viewed this dual role as:

Invaluable, in so far as it meant I was dealing on a daily basis with NESB/CALD artists across all disciplines, and was constantly reminded how difficult it was for them to assert their own voice and how marginalised they were by funding bodies at every level. (L. Marinos 2020, email correspondence)

Being uncharacteristically circumspect, Marinos (2015, interview) describes his time as ACMAC chair from 1995 to 1999 as 'stimulating but very challenging and frustrating'. Klika, ACMAC chair from 1999 to 2002 , more pointedly recalls the experience as one of a 'fight'. She was heartened in 2015 to find the 2000 policy still online:

It's good that it had some staying power beyond my time, because a concern one has when one goes through such a process of fighting for such a policy, is that once you go, the policy disappears. But it was worth the effort. (D. Klika 2015, interview)

This comment is telling in a number of ways. The metaphor of a 'battle' is illustrative of the antagonistic process Klika experienced within the institution. It highlights the AMA policy as a site of struggle and implicitly positions the Australia Council's leadership in equally 'combative' roles. Her reference to 'such a policy' suggests that the battle had become an anticipated and ingrained process. Klika also voices the concern that the pressure brought to bear by a 'champion' may dissipate when they leave the institution, with staff in executive roles retreating from, rather than continuing to implement, changes across the institution. The institutional rhetoric of support for greater diversity often relies on the charismatic and committed individual to present the appearance of a committed institution, yet, without such champions, there may well be 
'no commitment at all' (Ahmed 2012, 135). Ahmed $(2012,19)$ describes diversity champions as those appointed as 'diversity practitioners' who can also 'teach us about how we inhabit institutions'. That is, the champion needs first to be able understand the specifics of the internal 'institutional life'-a complex task that requires observation and relationship building before their role can become effective. The scope of the challenge for the 'diversity worker' is to manoeuvre through the institutional structures and cultures often built to resist change. My role as a senior policy researcher was, in part, to ensure that the transition between chairs and members maintained momentum for the policy.

According to Sirkin, Keenan and Jackson (2005), four elements contribute to effective institutional change: project duration, particularly time between project reviews; performance integrity, or the capabilities of project teams; the commitment of both senior executives and staff; and the additional effort that employees need to make to cope with change. The authors' key argument is that all four factors need to work in concert to deliver change. Yet, they are difficult to track because integrity, commitment and effort are all intangible and often need to be underpinned by consistent and effective leaders. While a chair appointed for a maximum of four years may be able to adjust institutional commitment for a limited period, they are reliant on subsequent leaders after they leave. Uneven support has dogged the history of the arts in a multicultural Australia. The Australia Council's leadership continues to appear reluctant to maintain its ambit (or commitment) of transforming the arts in Australia to better represent its multicultural society.

Therefore, transformational leadership, when challenged by complex issues, may prompt a return to the previous status quo. The inbuilt mechanism that requires fixed-term appointments to decision-making roles-including ACMAC, the governing members of the Australia Council and executive management—can also limit the momentum for change and meaningful legacy. Effective institutional leadership could exist in a productive relationship between transformational and positional leaders. Councillors need the leadership of the bureaucracy to be able to activate and negotiate change throughout the various staffing levels of the institution, while bureaucrats need the vision and influence of the councillors to maintain the relevance of the institution. 
The ACMAC chair had to find respect at the council decision-making level, while also engaging with the staff of the institution. This positioned the ACMAC chair as a central, institution-wide, relational leader in a space to increase the likelihood of longer-term change. There was a brief time when this did occur within the Australia Council. During the development of AMA 2000, Klika was ACMAC chair and Dr Margaret Seares was executive chair (i.e. both the chair and the CEO of the institution). The combined positional leadership of these women in influential roles, as well as their relational skills, initiated changes that led to a decade of resources allocated to implement an effective AMA policy.

The era of joint support for AMA continued when Jennifer Bott was appointed CEO (1999-2006). Bott (2015, interview) described Klika as 'thoughtful, strong and pragmatic', and as someone who also acknowledged the 'fight':

It was not sort of schlepped [passed] off as a kind of irritant or whatever. I respect Deborah for that. I think she had to fight for that. Then it filtered from the Council down in many ways. It made a lot of difference once AMA was taken very seriously at the governance table.

It was a significant challenge to have AMA taken 'seriously'-not as a slightly irritating friction that could easily be dismissed, but as a priority among competing priorities and contexts. Here Bott reinforces the hierarchy in the Australia Council, while also observing a change in the members of the governing body. Klika's use of both relational and transactional styles of leadership temporarily altered the status quo of governance. This change supports the experience of a battle, but also the attitudinal shift that enabled adequate resources to implement the AMA 2000 policy initiatives nationwide.

The Australia Council approved an unprecedented \$2.08 million for AMA initiatives over six years, averaging $\$ 350,000$ per annum (Keating, Bertone and Leahy n.d., 31). The per annum sum appears modest; however, the forward budget agreement-in-principle (conditional upon similar levels of funding from government) over six years is a commitment that is yet to be repeated. The Australia Council's recommendations to strengthen and commit long-term allocations to subsequent AMA policies were not endorsed. 


\section{The Reluctant Institution}

The management of AMA within the institution is indicative of another way of, as Bott puts it, being 'taken very seriously'; this presents opportunities for positional and transactional forms of leadership. Each of the many (six or seven) institutional levels require positional leaders who comprehend the issues and support the momentum for AMA strategies for arts sector transformation. Long-time senior bureaucrat at the Australia Council, Executive Director of Arts Funding and Engagement Frank Panucci (2015, interview) observes that, while it is now easier to 'articulate the diversity conversation', environmental limits remain in place:

Those famous two steps forward, one step back; you feel that a lot of times in that [multicultural] space. Part of it is about the arts and cultural space that, like a lot of these areas, are fundamentally determined by the general public and political discourse. While you think you have made the progress in a specific area, you can't remove it from the context within which you operate.

Awareness of context is an essential understanding required by any leader. Panucci is aware of the lack of traction, but deflects the reason for structural barriers in the arts onto society and government, which alleviates the Australia Council of any institutional responsibility. Klika, on the other hand, addressed the Australia Council's institutional responsibilities and achieved an unprecedented commitment to AMA during Prime Minister Howard's term, one characterised by a government that dismantled inclusive multicultural values and support structures (Ho 2013, 38).

Different approaches to change are expressed in the interviews with former ACMAC chairs, Marinos and Klika. These range from actively negotiating a positive impact where possible to taking a laissez-faire approach and leaving the outcome to 'market' or society. The motivations for Marinos and Klika to maintain their efforts stem from their respective leadership aims for change, but are articulated through different approaches. Their criticisms view policy intervention as being either inadequate or overbearing. Klika's (2015, interview) view of the role of arts policy is that it should not override creative intentions or be too prescriptive:

What I hope policy does is shift people's ways of thinking to be relevant to today's society. But I also recognise that sometimes policy can go too far and we find it difficult to decide if it's good or bad art because it's been ticked off under a policy. That's my problem with policy; sometimes you can't tell whether it's the cart or the horse in front. 
Marinos's view is that the policy levers are not direct enough. He argues that the Australia Council's lack of conviction for AMA shows through its unwillingness to ensure major companies address their consistently low levels of engagement with NESB artists:

The AMA policy is given some regard, but not pursued with much conviction. It's as though having the policy in itself is enough, to say 'this is what we've done'. But it's rarely implemented. If they do audit the major organisations for instance, I'm unaware that they have conversations that say-your representation is very low and do you have any strategies to redress that? (L. Marinos 2015, interview)

The conundrum is that having a policy 'to point to' can alleviate the pressure on action because it takes the place of 'doing' (Ahmed 2012, 86). Whether policy outcomes should be tied to government funding is a perennial discussion that involves quotas, compliance and the use of taxpayers' money. It frustrates Marinos and others to see structural change avoided by major organisations, such as state theatre companies. Indeed, the issues of government funding, quotas and policy remain live topics (Gonsalves 2017).

As a performer, Marinos remains close to the issues and observes improvements in other contexts that fuel his thoughts regarding the lack of comprehensive change for the arts in multicultural Australia:

Many companies have had an outstanding record with opportunities for Indigenous artists and I think that's a laudable thing. But it puzzles me, because it seems odd that the same thinking doesn't carry across to cultural diversity, in which areas they're lamentably woeful. (L. Marinos 2015, interview)

Marinos and Klika articulate a fundamental schism about implementation methods. Klika is tentative about over-prescribing to artists, while Marinos advocates prescribed outcomes to organisations. However divergent their views, both chafe against the lack of seriousness shown by the Australia Council in addressing the barriers experienced by NESB artists:

Council was a bit reluctant to implement policies they claimed to believe in, but stopped short of implementing in any meaningful way. It was never a demand that was placed on companies in terms of employment. (L. Marinos 2015, interview) 
The methods of policy implementation highlight the discord between intentions and the methods of delivering those intentions. Discord can inhibit change in a bureaucracy concerned about negative attention, particularly negative attention from politically influential chairs of major companies who are frequently affiliated with government in some way. However, there have also been small signs of change, with companies such as the Melbourne Theatre Company (MTC) and Belvoir Street advertising 'diversity' projects in 2018. In partnership with Multicultural Arts Victoria, the MTC Connect program aims to bring young people of culturally diverse backgrounds into the company as marketing and programming advisers (MTC 2014).

Klika (2015, interview) feels that institutional responsibility falls short in maintaining the steady momentum for change and advocating to government on behalf of NESB artists:

The Australia Council has to keep doing that work for those seeds to flower 20,30, 40 years on. I get depressed when they just maintain a status quo because that's easier, and they don't push the envelope with government.

Klika's comments conceptualise a succinct institutional leadership role for the Australia Council. The chances for this role to flourish, however, have diminished significantly since the disbanding of ACMAC. The impact of a void where once consistent advice was provided has affected the institution in several ways. It is difficult to keep abreast of developments in the multicultural arts sector because the structured opportunities for NESB artists to provide regular input across all artforms no longer exist. Subsequently, on the occasions when 'cultural diversity' may come onto the agenda, it is unlikely that all councillors (Australia Council board members) have had exposure across all the issues and artforms, or can speak with any confidence about the arts in a multicultural Australia. Executive staff members, therefore, become default advisers, most of whom are also unlikely to have in-depth knowledge of cultural diversity.

The embattled experiences of Marinos and Klika, as two ACMAC chairs appointed by different governing political parties, illustrate the Australia Council as a site of struggle regarding AMA. Disbanding the expert advisory function of ACMAC removed regular opportunities for the Australia Council's Board to engage with issues that affect NESB artists. Both chairs describe the unwillingness of institutional leaders within the Australia Council organisation to advocate to government on behalf of 
NESB artists, or to require that any organisations with secure Australia Council funding demonstrate and address 'cultural diversity'. These are two ongoing and unresolved leadership issues within the institution regarding the degree and means of intervention required to increase multicultural arts activity in Australia.

\section{The Fragility of Funding}

The Australia Council's main responsibilities are to disburse government funds to the arts through a national process of grant application and peer assessment. A positive outcome of a successful grant application is where 'money is translated into cultural artefact' (Hawkins 1993, 133). The steps to take in making an application include being aware of funding guidelines; approaches to, and negotiations with, arts funding staff members; comprehending and applying the guidelines for a submission; and awaiting the final decision. Each of these steps produce pressure points in the interactions between applicant and institution including how to interpret the guidelines that have taken staff innumerable rounds of meetings to agree upon, what kind of questions to ask the staff members who are trained to deliver information in a particular way, the intensive work required to produce a completed application and the machinery of processes (software and human) that produce a final result.

As part of the application process, the Australia Council collects data about each applicant's background. For example, the Australia Council Annual Report 2015-2016 indicates that 'disability' attracted \$375,000 in dedicated funds, 21 per cent of grants were awarded to regional artists or organisations, and \$9.9 million in funds were awarded to Aboriginal and Torres Strait Islander artists or organisations (Australia Council 2016a, $48,61)$. However, the report makes no mention of dedicated funding for multicultural artists or organisations. Despite multiple requests to the Australia Council since commencing my research, specific data on grants awarded to NESB artists have not been provided. This suggests a lack of transparency around these data. I have instead had to extrapolate information from various published Australia Council reports to build a picture of Australia Council funding to NESB artists.

The Australia Council's 2016-20 corporate plan (Australia Council $2016 b, 7)$ provides a statistic on support to NESB artists and organisations: 
Since inception, [1973] more than $14 \%$ of the grant funding allocated through our programs has gone to culturally and linguistically diverse groups. In 2015-2016, \$3.1m was awarded to artists and arts organisations who identify as belonging to culturally and linguistically diverse groups.

Three possible data scenarios emerge when the figures from the Annual Report 2015-2016 (Australia Council 2016a, 17) are intersected with those in the corporate plan (Australia Council 2016b, 10):

- If all grant funding is considered, including government initiatives and major performing arts (MPA) companies, NESB support equates to $\$ 3.1 \mathrm{~m} / \$ 173.8 \mathrm{~m}$ or 1.8 per cent.

- If funding that includes government initiatives and excludes MPA companies is considered, NESB support equates to $\$ 3.1 \mathrm{~m} / \$ 66 \mathrm{~m}$ or 4.6 per cent.

- If only Australia Council grant funding is considered (excluding government initiatives and MPA companies), NESB support equates to $\$ 3.1 \mathrm{~m} / \$ 50.6 \mathrm{~m}$ or 6.1 per cent.

These calculations are inferred from the Australia Council's published statistics for 'CALD artists and organisations' and expenditure reporting, and present a raison d'être behind the announcement of a target of ' $14 \%$ of funding [to be] allocated through our grant programs to projects by people from culturally and linguistically diverse groups' (Australia Council 2016b, 8). This transactional aim does not provide details as to how a 14 per cent target will be achieved.

\section{Navigating the System}

One of the inhibiting factors for individual NESB artists may be the lack of familiarity with the bureaucratic processes of applying for funding. In the late 1990s, Arts Queensland demonstrated leadership by 'accompaniment' through a series of innovative grant writing workshops in an attempt to even out the playing field:

They delivered a series of workshops where the multicultural artists would act as a funding panel to assess [anonymised] real grants. It honed in on the technique of writing a grant. Afterwards, there was a 70 per cent increase of grant applications from multicultural artists-that's huge. (P. Couros 2015, interview) 
Reversing the hierarchy of expertise on excellence improved NESB artists' comprehension of how to prepare better grant applications. Increased numbers of grant applications illustrate the workshops success; the workshops can also be seen as opportunities for artists to develop creative leadership. The value of any grant, beyond the money, is the recognition and level of trust it signals from peers.

Gaining that recognition is further complicated by the perceived hierarchy of genres within specific artforms. The aesthetic hierarchies perceived between innovation and cultural maintenance produce friction during grant assessment meetings. A Dance Board and ACMAC member observed:

How an excessively marked interest in innovation undermines the possibility of funding other types of work dealing with cultural heritage. Cultural maintenance was viewed as both a matter of the group the applicant belonged to, and of the way the application was structured. (ACMAC n.d.-a)

This memory articulates the flawed perception that innovation and heritage are mutually exclusive, which AMA 2000 attempted to address by profiling the links between tradition and innovation (Australia Council 2000). This excerpt also highlights that the need to articulate such aesthetic connections applies mainly to NESB artists. This issue was raised again in 2017 by NESB artists. For example, dancer and choreographer Aruna Gandhi reflected that she felt that her lack of success in arts grants applications was because her Bharatanatyam practice was considered neither contemporary nor innovative (Castagna 2017).

When faced with a low level of funding and a lack of employment opportunities in the creative sector, some artists have taken the entrepreneurial response of establishing creative enterprises (Idriss 2018, 95-117). For example, CuriousWorks established a fee-for-service role, drawing on the media technology skills of those in the company. This income stream supported the company's other aims to deliver not-forprofit projects with community partners, because even secured grants were inadequate to deliver all the ambitions of a project:

Your ideas are bigger than funding anyway, and so it has to be supported elsewhere. This is in the context of not being from a middle class where you only have to look after yourself. So you have to have a solid business model. (S. Shakthidharan 2015, interview) 


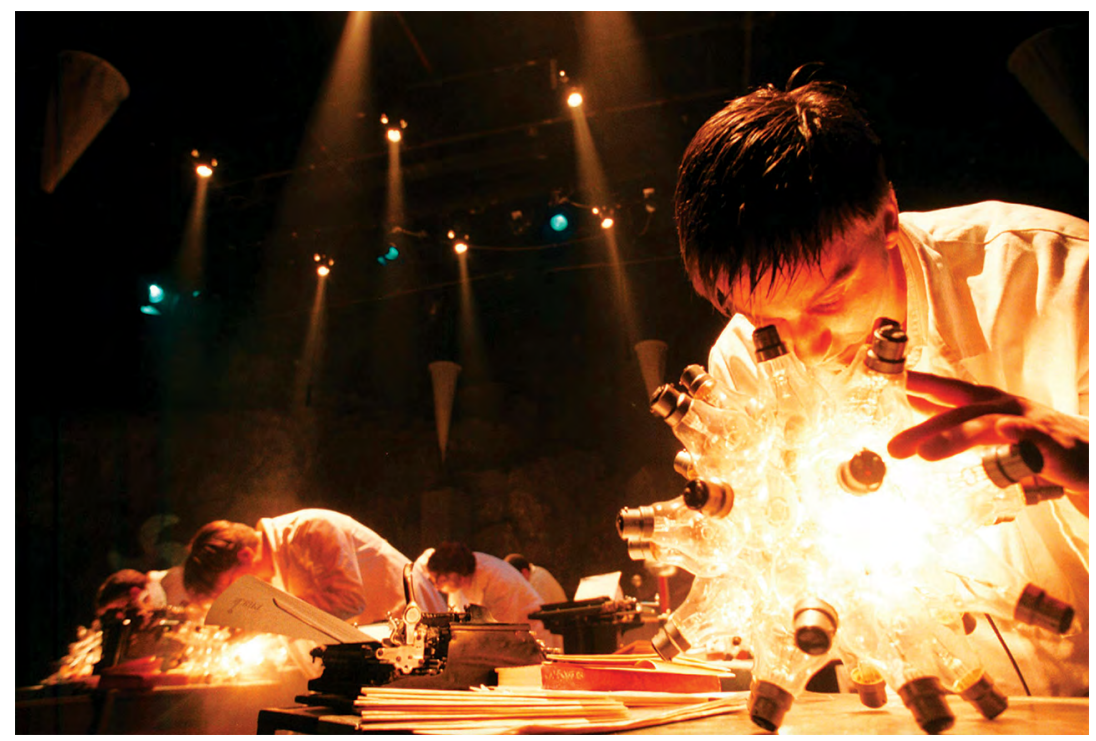

Image 18: Konstantin Koukias, Tesla-Lightning in His Hand, 2003

Photographer: Lucia Rossi

The issue of class raised in this quotation points to the uneven family support for creative pursuits experienced by NESB artists. Shakthidharan's solution to maintain a 'solid business model' exemplifies a pragmatic response to the friction caused around levels of funding, but also points to the strategies and efforts being made to maintain the business.

The fragility of funding to the small to medium (S2M) sector increases because the state art agencies and the Australia Council agree that if one agency stops funding a company the other will also 'defund' them. Koukias had kept his experimental opera company, IHOS, in production for 25 years on small amounts of organisational funding (see Image 18). Several years ago that persistence looked successful:

We'd just opened a massive opera at MONA [Museum of Old and New Art] with seven sold-out performances and all on budget, when IHOS got de-funded. It was only a matter of time before the state would pull the plug and I couldn't keep begging from patrons. I had to rely on a lot of teaching to survive because I was only ever on a stipend of $\$ 10,000$ a year. (K. Koukias 2015, interview) 


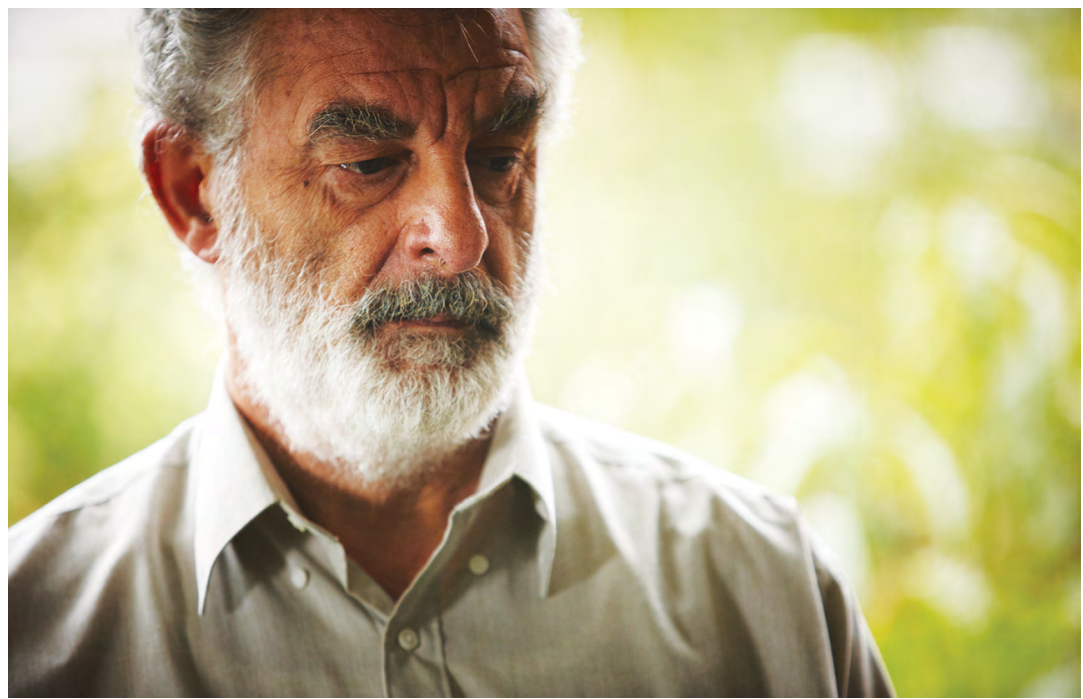

Image 19: Lex Marinos, The Slap, 2011

Photographer: Ben King

Courtesy: Matchbox Pictures

These two examples reveal the tenacity of the NESB artist to manoeuvre around low levels of institutional support. Both CuriousWorks and IHOS are companies that provide enormous creative opportunities for many NESB artists. Therefore, any reduced capacity through loss of funding impacts negatively in a ripple effect.

Support for the arts in Australia fractures along lines of historical privilege. Marinos (2015, interview) (see Image 19) is highly conscious of the inequity in funding and accountability that quarantines MPA companies from failure compared to the vagaries of funding experienced by creative risk-takers in S2M companies:

The majors are the ones who've been able to parlay their position with sponsorship and [a] subscriber base and can most absorb any cuts. The money should go to those smaller independent companies who are trying to do new work and advance the evolution of the arts.

This highlights the tense struggle for funds, particularly in the S2M sector, where the creative risk-takers are often located (Stevenson et al. 2017, 12; Eltham 2016). A low-risk approach to questions of excellence reinforces this tension. A model put forward by Kalantzis and Cope proposes turning the current funding model on its head. They suggest 
that, because low-risk projects emphasises the known, organisations with proven track records should be provided with short-term funds, whereas high-risk artists with future potential should benefit from a 'long-term venture capital approach' (Kalantzis and Cope 1994, 31-32). Given that many NESB artists are perceived to be high-risk, this (albeit utopian) approach could reverse the trend of lower support for their work.

Fewer multicultural arts organisations are now federally funded. Since 2016, only seven of the 128 funded organisations (5 per cent) have a specific multicultural arts focus and these received $\$ 1.6$ million of the allocated $\$ 28$ million (6 per cent) (Australia Council n.d.-a). This shows that the Australia Council still struggles to communicate effectively or demonstrate relational leadership across the increasing diversity of Australia's population (ABS 2017). This is a leadership issue that will need to be transparently addressed if they are to increase their grant approvals to 14 per cent for NESB artists and groups (Australia Council 2016b).

For institutions like the Australia Council that are attempting to engage with such diversity, strategies of 'accompaniment' (Lynd and Lynd 2009, 93) or 'attunement' (Gibson 2005, 273) could be employed. Accompaniment respectfully shares skills while attunement adjusts for dissonance, tries to pick up less common signals, and sets up a feedback loop with the aim of developing trusted relationships. The frequency and manner in which the institution tunes in to the messages of artists and advocates indicates how 'seriously' an issue is taken. In the case of the arts in a multicultural Australia, the amount of influence the institution is prepared to exert upwards and outwards is another indication of its leadership intentions. The past decade has seen a paradoxical shift by the institution away from providing regular opportunities to meet with NESB artists, while simultaneously attempting to develop a cohesive approach to diversity issues through the CEF.

\section{Cultural Engagement Framework: Between Aspiration and Implementation}

Within the Australia Council, all 'social' diversity policy areas have come under the umbrella of the CEF since 2008. The CEF views diversity as a 'great cultural asset that leads to greater artistic vibrancy and innovation' (Australia Council n.d.-b), an approach that resonates with the instrumental productive diversity argument (Cope and Kalantzis 1997; Bertone 2002; Ho 2013, 37-38). The 2011 iteration of the CEF foregrounds legislative compliance. The Australia Council claims 
a transformational leadership role through the CEF's remit of integrating strategies for artistic excellence across the diversity of Australian society, encouraging participation and enjoyment of the arts, and ensuring council services are socially and culturally inclusive (Australia Council 2011).

The framework is not described as a 'policy' but as a 'mechanism' to engage with diversity and increase 'the relevance, dynamism and reflection of contemporary Australia through the arts'. 'Diversity' is specified by the Australia Council as encompassing 'first nations people, children and young people, older people, people with a disability and regional and remote Australia, and with a focus on disability' (Australia Council 2016a, 52). The focus on disability aligns with government legislation. The CEF principles incorporate diversity through:

- respect and interaction

- dialogue: through access to resources

- artistic excellence: to produce greater artistic vibrancy

- inclusiveness: to encourage mutual respect and harmony

- belonging: to generate a sense of identity

- community building: to strengthen communities (Australia Council n.d.-b).

The aims to foster artistic vibrancy and harmony are inspirational, if generic, values. The ideals appear achievable because actions such as dialogue, encouragement and interaction can be demonstrated by Australia Council staff, even though these are difficult to gauge. Whether the principles are sufficient to generate shifts in Australian cultural life is questionable, given that the crux of the CEF remains one of resource allocation and that, 10 years after its inception, the detail and timing to enliven the CEF is yet to be published.

The institutional responsibility for the CEF sat with Executive Director of Arts Funding and Engagement Frank Panucci (2015, interview), who views it as a 'breakthrough' in the maturation of the Australia Council:

The CEF has put a way of structuring and talking about itself internally, in a different space than when we were doing the Arts in a Multicultural Australia policy. At times I think some parts of this organisation thought AMA was either an imposition or somewhere they could push stuff to. There's nowhere to push things anymore. If you don't address it in this place, then there'll be someone that will ask the question of why it wasn't addressed. 
Here Panucci acknowledges the institutional shunting of responsibility for AMA identified since the 1970s. 'Pushing' articulates the energy expended to avoid engaging with AMA. The description to 'push stuff' captures the internal friction of institutional responsibility. However, the CEF notwithstanding, the current absence of dedicated institutional responsibility for AMA brings into question the capacity to generate traction. In reality, there may be little difference between the perception that AMA was an 'imposition' and the quasi-policing role of CEF champions to 'ask the question'.

The internal institutional focus of the CEF requires the ideal proposition of active endorsement by all staff, led by 'champion' advocates. Another intent of the CEF is to stimulate change in the arts sector; this is relevant to Marinos's question about how the major arts organisations are encouraged to perform. Panucci (2015, interview) claims that a productive shift has occurred within the 'open' grants programs:

The alignment in the general programs to the needs of artists of cultural[ly] diverse backgrounds is better than it was 10 or 15 years ago. At times you still need specific interventions. But that becomes a resource question. So we have to be vigilant in monitoring the outcomes.

This statement is arguably inaccurate about the support to CALD artists on two fronts. The alignment to their needs has not improved because they remain underfunded. Panucci's statement also suggests that monitoring is the main mechanism to understand the experience of NESB artists in the absence of dedicated resources. The CEF is an institutional internal model and difficult to prise open, but those in a close outer circle can provide some perspective.

Executive Director of Carriageworks Arts Centre Lisa Havilah (2015, interview) suggests that those who claim a 'lack of resources as a rationale do not have diversity at their core'. Pino Migliorino, a specialist in multicultural business advancement, is the only consultant to have formally reviewed the CEF. He views the 2015 federal budget decision (to move significant funds from the Australia Council back to the Department of the Arts) as fatal to the CEF's implementation: 'I thought, that's [the CEF] off' (P. Migliorino 2015, interview). This raises questions about the centrality of the CEF. Migliorino found that the CEF had 
'compartmentalised' each of the areas for attention and had become what he described as 'an internal mechanism' limited to human resources. The issue of internal resourcing also came to the fore:

There are leaders in the executive, as well as project officers, who want to be employed fulltime to do this work, but can't because they have to do other jobs. The philosophy of creating this in terms of an 'on top of' approach doesn't work. (P. Migliorino 2015 , interview)

The scope of 'cultural diversity' leadership for the CEF has, therefore, been limited within the institution. Panucci argues that 'CEF champions' will deliver its aims; however, Migliorino's (2015, interview) observation is that 'there's a policy void right now. And no one's championing it. I have not heard anyone talk about arts for a multicultural Australia'. Alongside the issue of resources (human and financial), relational leadership is required to identify and embed diversity principles in Australia Council work practices:

Fundamental principles should be driving the organisation. What are the access principles? And in those access principles, the organisation will tend to deliver across what is fundamentally a very narrow band. So this becomes remedial. (P. Migliorino 2015, interview)

The term 'remedial' suggests both a 'back to basics' corrective action and the process of triage associated with an emergency to remedy a crisis or collapse. Both actions identify the severity and level of priority of the situation before treatment. 'Remedial' implies the institution is retrorather than proactive: 'We know that non-English artists and audiences are not engaged yet. So they require quite specific tactics' (P. Migliorino 2015, interview). Attending to the needs of specific groups generates friction between competing priorities, but Migliorino further argues that the institutional support must meet the infrastructure needs and cultural competency in the existing services' of NESB artists.

Migliorino identifies two significant gaps that the institution needs to address for cultural diversity to thrive, gaps that fall between aspiration and reality:

We must make do, enmeshing our desires in the compromise of practical action. The bridge we stepped off is not the bridge we stepped upon. Yet to cast away the memory of the first bridge 
denies desire. To pretend it is the same as the second bridge is the baldest lie of power. It is only in maintaining the friction between two subjectively experienced bridges, the friction between aspiration and practical achievement, that a critical analysis [of global connection] is possible. (Tsing 2005, 85)

NESB artists 'make do' with less funding and with fewer employmentbased arts networks than their English-speaking background peers. The corporate history or memory of AMA initiatives resides in two or three remaining staff members who could be considered as those on Tsing's 'first bridge'. Those on the second bridge are arguably those staff 'champions' or intermediaries who are expected to understand, promote and monitor the CEF's aims. The CEF may be future oriented but monitoring alone will not generate future change. As with any policy area, a negotiated agreement requires leaders to establish the agenda and associated research, and provide vision, aptitude and internal political experience.

The manner in which the Australia Council profiles its support for cultural diversity contributes to a multicultural arts milieu and underpins the trust that NESB artists have in it as an institution that distributes funds. In the 10 years since the introduction of the CEF, the term 'multicultural' has all but disappeared from Australia Council documents to be replaced by 'cultural diversity'. In the council's 2016-20 corporate plan, the word 'multicultural' is completely absent, while 'cultural diversity' appears once. Further, from early 2018 onwards, AMA policies have disappeared from the Australia Council website. The Australia Council's inability to acknowledge its previous corporate role around AMA, failure to use the term 'multicultural' and lack of a cultural diversity action plan indicate institutional reluctance to engage with this sector of the arts. More broadly, this reluctance can be seen as a refusal by the current leadership of the Australia Council to proactively engage and take action on the issues affecting this sector.

\section{Establishing Trust through Expertise}

Regular engagement with advisory experts within the institution can test or generate trust in institutional processes and also develop trusting relationships between staff and peers. I argue that, were this to occur, a more permeable institution would be created that would maintain its relevance across the arts sector. 


\section{The ACMAC Member}

The ACMAC model was central to maintaining momentum for AMA because it held a robust internal position with external links to advisers and experts. ACMAC members held increased status and legitimacy because they engaged in broader debates beyond the assessment of grant applications. The government appointed members for three-year terms to artform boards, and then NESB artists were invited onto ACMAC (Keating, Bertone and Leahy n.d., 49). ACMAC was the only committee with formal links to other artform board members. Despite being the only NESB artists at grant assessment meetings, their positional leadership was increased because they had access to two council chairstheir own artform board and ACMAC. Many recall the productive and convivial atmosphere of ACMAC meetings despite having, at times, tense policy debates.

ACMAC members were exposed to a rigorous, if informal, training ground, that increased their capacity to articulate expert knowledge about art practices in a multicultural Australia. It also increased their ability to discuss the issues and develop and critique the effectiveness of specific AMA strategies. Multicultural audience consultant Fotis Kapetopoulos (2016, email) describes the relational leadership within the 2006-08 committee as:

Exceptional, as it was not ideologically bound, as much of this area can be, but rather had a vision to make diversity an essential creative and economic focus of the arts. There was a diversity of people, with divergent views who came together as experts.

Very few, if any, formal opportunities for this level of national professional development for advocates for the arts in a multicultural Australia that directly link to the Australia Council now exist.

The link to peers on other artform boards elevated the standing of NESB artists, even if they were initially uncertain or ambivalent about what it meant to be ACMAC members. Then theatre director Teresa Crea was an ACMAC member during the early 1990s, one of the more progressive eras for AMA policy implementation. She recalls the combined experience and knowledge of practitioners and academics as productive for the institution: 
The leadership was most effective when the committee was chaired by individuals with a deep philosophical understanding of the field with a mix of practising artists. Simply ticking [an] NESB box was not enough for leadership and guidance on this complex issue. The committee acted at times very much as a 'brains trust' identifying issues and potential strategies to support and articulate AMA policy. It was one of the few places where issues of policy and practice were discussed at a deeper level. (T. Crea 2016, email)

Crea articulates the value of the creative leadership of 'politicised' NESB artists and the institutional leadership of academics. Together, they broadened the conceptual thinking of ACMAC and, by extension, the artform boards. This relational leadership drew on the collective skills of the members. Academics contributed to institutional leadership through their capacity to analyse policy issues that could impact NESB artists' experiences. This knowledge base of practice, theory and policy enabled the committee to bring together a range of political, historical and practical perspectives critical for formulating long-term strategies. The comments by Kapetopoulos and Crea suggest that ACMAC demonstrated characteristics of distributed leadership (discussed in Chapter 2), which rotates and draws on the different skills of the members to lead as needed. When displaying distributed leadership, ACMAC can be seen as a highly functional network.

An alternative perspective suggests that ACMAC brought tokenistic legitimacy to the Australia Council, and was more like a 'paper tiger' (L. Marinos 2015, interview). Curator and 1990s ACMAC member Nikolas Tsoutas (2015, interview) agrees:

It was a political excuse to have the Arts for a Multicultural Australia because it sounded right for both parties [Australia Council and multicultural advocates]. They were paying lip service to multiculturalism rather than addressing the need for change.

These multiple perspectives highlight the institutional and multifaceted 'tug of war' that is characteristic of AMA. ACMAC members demonstrated intellectual, cultural and artistic leadership across all artforms, something that was not achieved elsewhere in the carefully guarded artform silos. Yet, on the other hand, ACMAC was a place to 'push stuff' to. It was not given enough power or resources to actually effect the change it continually articulated. Regardless, the legacy of ACMAC resides in the numbers of artists who were exposed to ways to conceptualise and act on 
diversity in the broad scope of Australian arts. That legacy is significant because it built confidence in those members as creative leaders who could also learn about and attempt to influence the direction of an institution. In this manner, despite its apparent reluctance to deal effectively with some of the issues raised by ACMAC, the Australia Council demonstrated a level of institutional leadership through its support of ACMAC.

\section{Tension at the Business End}

In the context of the Australia Council, peers are discipline experts who are brought into the sphere of the institution to provide advice or assess funding applications. During this process, artist peers become trusted experts via their recommendations on the awarding of grants. There is overwhelming endorsement by the arts sector and the Australia Council for the principle of peer assessment and arm's length decision-making from government (Parliament of Australia 2015). My empirical research highlights the different ways in which trust is conferred or dismissed through institutional processes, many of which revolve around behaviour and discourse. As Bourdieu (1984, 461-62) notes:

This crossing-point between experience and expression is where the professional producers of discourse come in; it is here that the relations are set up between the experts and the laymen, the signifiers and the signified. The dominant language discredits and destroys the spontaneous political discourse of the dominated.

The process of 'destroy[ing] the spontaneous ... discourse' applies to the microcosm of an assessment meeting. It encapsulates committee members' experience of a muted discourse, if not silence, when outside the supportive environment of an ACMAC meeting. Within the arts grant assessment process, for example, all peers are nominally considered to be 'experts'; however, what Bourdieu calls the 'professional producers of discourse' invariably take the lead. Within the ACMAC framework, one NESB peer attended each assessment meeting. Regardless of their creative expertise, their vocabulary and expressions sometimes differed from those of other peers; in such cases, influencing funding choices away from the familiar was a challenging task. To be able to articulate an alternate discourse that challenges the dominant one in the context of a meeting is a precise skill beyond advocacy. It requires relational leadership to establish trust and respect with other peers. 
Although writing of cultural taste, and not about government grant assessment processes, Bourdieu $(1984,6)$ succinctly captures their political dimensions:

The science of taste and cultural consumption begins with a transgression that is in no way aesthetic: it has to abolish the sacred frontier which makes legitimate culture a separate universe, to discover intelligible relations which unite apparently incommensurable 'choices'.

To transgress is to cross into unfamiliar and often unacceptable territory. To assess an arts grant is a cultural-political-economic act in which discussions of aesthetic merits are subsumed beneath budgetary considerations. In the case of ACMAC and the roles of individual peers in grants assessment processes, their commentaries can be seen as transgressions that challenge the 'separate universe' (Bourdieu 1984, 23) of what is conceptualised as legitimate culture. Tensions build because, as the only NESB artist at grant assessments, there are assumptions (by everyone else in the meeting) of cross-disciplinary multicultural arts knowledge and expertise across the range of applications. The issue of whether the NESB artist and their knowledge is trusted by the other peers depends on the experience of those others peers and the ability of the group to unite 'apparently incommensurable choices' (Bourdieu 1984, 23) — which is usually achieved at some point in the meeting. The NESB artist's presence and the assessment group's final recommendations are then used to legitimise grant allocations by the Australia Council.

Persistent assertiveness is required to counter the conflicting pressures in the elite atmosphere of those meetings. ACMAC members noted that they felt like outsiders at such grant assessment meetings. This feeling was even acknowledged by those with extensive organisational experience and expertise, including Tsoutas, a previous director of several contemporary arts organisations. Tsoutas (2015, interview) recollects his experience in the 1990s:

You were sort of stigmatised. You were there, not really to be able to engage and represent the whole oeuvre of the policymaking in the OzCo [Australia Council] or visual arts or whatever, because you were limited to talking about multiculturalism. The question of trust was ever present. The problem was that they couldn't easily dismiss me because my vocabulary exceeded the bounds of the cultural discourse. 
As a practitioner expert in the area of multiculturalism and the arts, Tsoutas was well positioned to articulate issues of multiculturalism, art, policy and processes; this included an acute awareness of how he was perceived, both in meetings and in terms of the overall process. Tsoutas's experience reflects Bourdieu's $(1984,462)$ argument regarding the ways dominating discourse is adopted by the dominated. However, in this case, the expert whose knowledge 'exceeded the bounds of cultural discourse' (Tsoutas 2015, interview) was required to be more erudite than the other experts in the room. This is a rare skill in Australia, where the type of education that develops knowledge of multicultural issues is unlikely to be found in the arts academy or in the informal mechanisms of family life (Idriss 2018).

\section{The Question of Targets}

Complementing the requirements of setting directions and developing policy was the requirement of monitoring the progress of grant and initiative successes. For most of its existence, ACMAC reviewed an annual AMA report that included statistical data. This was even though, as Crea (2016, email) states:

The struggle for and against 'quotas' and 'definitions' of NESB was a constant—difficult, but necessary. There were too few other avenues to help quantify what was happening in the field.

This requirement was established at the time of ACMAC's inception, with data circulating internally and only intermittently being made public. For example, former council chair Hilary McPhee (1995) reported growth in expenditure on AMA of 7.9 per cent between 1988-89 and 1993-94. Marinos, as chair of the CCDB, challenges whether levels of expenditure was across all artform boards. This query is also endorsed by Hawkins (1993, 118). According to Marinos (2015, interview), 'NESB artists were very strongly over-represented within our fund, and it managed to make the under-representation in the other funds look better than they were'.

The AMA targets could also be limiting, and not simply because they were much lower than Australia’s demographics:

Once you reached that quota, it was cut, so it was no longer about merit. If [an] NESB applicant was assessed later in the meeting, they were chopped because they were not in the milieu of [Australian arts]. Your name automatically, whether you're first 
or second [generation NESB], put you into that multicultural thing and they had Buckley's [no] chance of getting any funding. (N. Tsoutas 2015, interview)

Targets within the Australia Council's model were a point of compliance to limit a result to a maximum rather than minimum quota; this is described by Ahmed $(2012,106)$ as a 'minimalist cop-out phrase'. Compounding that minimalist ceiling is whether the target reflected the multicultural composition of Australia. In 2015 the Australia Council's view was that targets were too complicated because of the increasing complexity of Australian demographics:

An agency would not be able to go down a target road unless they were in an environment where targets were considered to be an appropriate way of doing things. Wouldn't you be saying — targets [for] around that demographic of people who are within the first five years of their arrival in this country and the most difficult period of settlement? (F. Panucci 2015, interview)

Linking the issue of targets to an 'appropriate' environment allows the institution to evade the question of targets and appears to close it down as an option for consideration. Panucci, however, articulates some of the nuances that would need to be considered at a micro-policy level in order to engage with the increasing complexity of cultural diversity through migration and intergenerational change. Twelve months after my interview with Panucci, the Australia Council advised that it would aim for 14 per cent grant allocations to CALD artists and organisations by 2020 (Australia Council 2016b). This was an internal shift; it was not prompted by any political shift in the council's context. It implies an awareness of lagging performance and the need to show institutional leadership again for multicultural arts. Further, it brings into question the issue of trust between the Australia Council and its companies, because it incorporates a tacit acknowledgement that the arts sector is performing below par where multicultural arts are concerned. The institution shows transactional leadership, which appears to be an effective form for an arts funding agency with limited resources, enabling it to engage more broadly with the sector. For transactional leadership to be effective, however, specific transactions need to be articulated. The announcement of a 14 per cent target would be more convincing were it accompanied by transparent expectations of what the institution requires of its funded organisations. Arts Council England (ACE), for example, publishes results of company 
inclusion in programming and employment and their expectations for organisational cultural diversity, and also produces materials to assist organisations in achieving those expectations (ACE n.d.-a).

\section{Post-ACMAC Peers}

The evaluators of AMA 2000 identified challenges faced by ACMAC regarding the recruitment of members, compliance by artform boards and the capacity of board peers to represent issues regarding the arts in a multicultural Australia, and recommended that:

No case was found for disbanding the Committee. On the contrary, it was felt that the role of ACMAC should be strengthened, drawing in more Council members and external advisers. (Keating, Bertone, Leahy n.d., 4)

The senior executive developed a new structure that drew only from external experts invited onto the committee. This 'relaxing' of committee appointments may have indicated the start of a shift to artists becoming 'ad hoc' advisers. Peers are now contracted on a rotating basis for several assessment meetings. Media artist and cultural producer Panos Couros, an ACMAC member during the development of the 2000 policy, was an invited peer in 2016. He participated in three assessment meetings and found negligible multicultural awareness:

Because if it wasn't for me in that room-particularly for the literature round, some really outstanding writers from non-Anglo background would not have been considered. I had to put a case for them, saying: 'This is what makes the fabric of our society, to understand our own separate and combined mythologies and backgrounds. So this is really important work. Why aren't you even considering it?' All of a sudden we got four NESB artists up in the top six or something like that. (P. Couros 2015, interview)

The first issue raised by this recollection is that ACMAC was folded prematurely. One of the outcomes of ACMAC was the increased capacity of both novice and experienced NESB artists to assess and advocate for quality arts projects, particularly multicultural art projects. Another issue suggested is that Australia Council staff members are either inexperienced or inattentive to CEF issues within this new system of short-term peer appointments. This may explain why there were no briefings about CEF areas at the meetings Couros attended; this, in turn, would reinforce the lack of knowledge about CEF on the part of other assessment peers. 
A third issue flagged is future professional development opportunities for novice advocates and assessors, both to develop the skills and abilities of advocacy and peer assessment and to critique the overarching values still evident in the arts. Couros demonstrated leadership in speaking up in support of work that he considered marginalised within the assessment process. His was a style that arguably developed through multicultural advocacy experience with Arts Queensland and his time with ACMAC.

ACMAC acted as an informal professional development opportunity for artists to hone their skills in advocacy and sector leadership. It was diluted when it was decoupled from the arts board model to an external expertonly panel, because the responsibilities held by ACMAC were positioned at a distance from the main business of grant assessment. This has resulted in reduced opportunities for novice multicultural advocates. The eventual disbanding of all artform boards and replacement with short-term peer appointments has not redressed this imbalance. The 19 per cent of CALD peers (Australia Council 2016a) cannot all be assumed to have adequate and informed experience about multicultural arts policy and discourse. The capability for multicultural advocacy relies on bold, knowledgeable, articulate and experienced peers who can advocate within the strictures of the institution. This range of capacities are found in transformational, transactional and relational leadership styles, all of which are needed at different times, even in the same grant assessment meeting.

\section{Traction Afforded through Networks}

ACMAC also facilitated bringing NESB artists and cultural practitioners into local and international dialogue through discourse and exchange. ACMAC initiatives have included conferences, publications and roundtables to enhance the traction for multicultural arts practices. ACMAC encouraged critical thinking because it placed multicultural discourse within the wider sphere of the arts.

\section{Traction through Critical Discourse}

During the 1990s, ACMAC members identified the need for critical discourse in Australia and proactively used their positions to stimulate discussion in the arts: 
One of the reasons [the Australia] Council was unable to make any informed decision was because there was limited literature generated from within Australia. ACMAC decided to fund a publication which was the first one that tried to define, or engage with the discourse. [Culture, Difference and the Arts] is a critical publication. (N. Tsoutas 2015, interview)

ACMAC remained proactive in this aspect of its role. Such initiatives enabled ACMAC members and other Australia Council staff to keep abreast of AMA issues and how the field (including practitioners, academics and bureaucrats) was addressing the arts in a multicultural Australia. The 2000 ACMAC body was able to broaden the scope of discussions in Culture, Difference and the Arts (Gunew and Rizvi 1994) by commissioning two international conferences: Globalisation, Art + Cultural DifferenceOn the Edge of Change held in Sydney in July 2001, and Empires, Ruins and Networks: Art in Realtime Culture held in Melbourne in April 2004 (Art in Society n.d.). The networks and positional leadership of Tsoutas at Artspace, a contemporary arts centre in New South Wales, Papastergiadis at the University of Melbourne and ACMAC working in concert enabled lively engagement with ideas of multiculturalism and creative difference in Australia.

The evaluation of AMA 2000 found that these were among the most recognised initiatives of ACMAC and the 'majority view was very positive' (Keating, Bertone and Leahy n.d., 39). The continuation of the conferences was seen as 'consistent with the leadership role of the Australia Council' (4). Both conferences aimed to develop 'intellectual and artistic frameworks for Australian multicultural arts within an international context' (32). The conferences generated traction for the artists when they saw themselves among their NESB peers, which, for many, was their first experience of this. Opportunities for NESB artists to come together nationally have since declined, but are well attended when they do occur. Crucially, the scale and scope of the 2002 and 2004 conferences are yet to be repeated.

After the second conference, ACMAC hosted a roundtable with the local and international conference presenters to generate additional strategic input into the AMA policy. An internal report summarised the first roundtable. Facilitated by Annette Shun Wah, the participants (a veritable who's who of cultural diversity practitioners and theorists) considered future prospects through two main discussion points. The first was to 
'break down the dominant perspective which governs cultural industries' and the second was to 'deal with cultural difference beyond the categories of "multicultural" and "indigenous" (ACMAC n.d.-b, 1).

The roundtable developed practical suggestions based on the conference debates to gain greater traction for the arts in a multicultural Australia through art practices and positioning 'cultural difference' as the site of change:

1. The aesthetic question of cultural difference needs to be foregrounded. In promoting work dealing with cultural difference we need to look at the quality of the work rather than just ticking boxes, counting heads and filling quotas.

2. Cultural difference is the hub. Cultural difference is the cutting edge of history. (ACMAC n.d.-b, 2)

The first point places aesthetic developments that engage with cultural difference at the centre of the debate and outside the paradigm of the quota. American artist, advocate and an Empires, Ruins and Networks conference presenter Coco Fusco advised the group to orchestrate both narratives: the need for quotas (to generate grant income) and the disavowal of them (as cultural critique). The second point centralises cultural difference and positions cultural diversity as both the mainstream in Australia and a driver for change. During the roundtable, presenters expressed the view that a historical transformation was taking place catalysed by issues of cultural difference; however, this is a transformation that is yet to be found in Australian cultural institutions.

One ambitious proposal arising from the roundtable was to develop a workshop on Art + Cultural Difference + Global Collaboration aimed at maintaining a strong level of critical dialogue and at facilitating collaborative art projects within a national network of artists, academics, funding agencies and sponsors (see Appendix D). In effect, the workshop aimed to establish an Australian version of iniva (n.d.), a London-based research and exhibition centre for cultural diversity. The partnerships to be brought into the workshop were envisioned as community organisations, cultural producers, donors and sponsors, universities and art colleges, state and federal arts agencies, and public galleries and art institutions. The value of the proposed workshop model was that it could be scaled up or down and could be applied as a partnership model for culturally diverse small to medium enterprises. This process of discussing and developing 
the workshop project encouraged relational leadership between the participants to equitably share knowledge and ideas to reach beyond their own specific interests.

\section{The Struggle for an Australian Multicultural Arts Company}

Internationally recognised multicultural arts companies such as UKbased Akram Khan, iniva and Rich Mix serve as one measure of success of a multicultural society. However, all attempts to establish such a flagship in Australia have foundered.

The proposal of the Art + Cultural Difference + Global Collaboration workshop was not taken up by ACMAC. ACMAC considered that their existing AMA initiatives had adequate momentum to match the intentions of the roundtable. This was the first failed moment to establish an independent cross-disciplinary flagship for the arts in a multicultural Australia. One ACMAC member described the roundtable discussions thus:

I could have been at an ACMAC meeting working on our policy. I found no major differences in the roundtable discussions. In fact, the discussion reinforced our direction, especially the incubator project we are working on, and many comments echoed responses to the current Planning for the Future [corporate plan] document. (ACMAC n.d.-b.)

Aside from resourcing issues, this comment points to a shortcoming in leadership by ACMAC. At the time, members believed that their committee's existence and position of influence within the institution was sufficient to generate change. From this perspective, the members lost sight of long-term and sustainable ways to generate traction. The potential offered by the workshop proposal did not gain traction, and the associated networks were not leveraged into action. It appeared there was a reluctance to be bold and ambitious within the Australia Council executive and ACMAC began to tailor its aims much more modestly, but not before delivering its highest profile political event.

The last chair of ACMAC, Nicola Downer, attempted to generate confluence for AMA with state and federal governments at a one-day symposium held at Parliament House, Canberra, in 2007: Multicultural 
Arts: Cultural Citizenship for the 21st Century (Australia Council 2007). Downer arranged unprecedented access to federal arts, citizenship and foreign affairs ministers and many NESB artists performed at Parliament House for the first time. It had been decades since state and territory arts managers had come together in discussions with artists and cultural practitioners to spearhead strategic partnerships for multicultural arts. While it was not uncommon for those agencies to meet, it had been a long time since they had all come together to impress the benefit of multicultural arts practices.

The opportunity to meet federal parliamentarians drew the CEOs of state and territory government arts departments. The event increased the positional leadership role of the Australia Council among the multicultural sector and was claimed to have generated greater traction at each state's arts agency, which 'would look more closely at their existing multicultural policies and programs' (Australia Council 2007). At this time, aside from Arts Victoria (later Creative Victoria), most arts agencies did not have a multicultural policy. Alongside Creative Victoria, several other arts departments have since recognised the creative importance of multicultural diversity in their mission statements.

Downer used her political influence for the benefit of the AMA policy and demonstrated positional and charismatic leadership in doing so. It was to prove to be the last major event for ACMAC. Gouriotis, a former executive director of Casula Powerhouse Arts Centre, recalls being inspired by Downer's positive energy for ACMAC. Although an Australian Labor Party member and against prevailing perceptions, Gouriotis (2017, email), commenting on the appointments of Klika and Downer, claims that the 'Australian Liberal Party did more for ACMAC than the Australian Labour Party'. This acknowledges Klika and Downer as positional leaders (both had influential relations within the Australian Liberal Party) and relational leaders who advocated for AMA within in their own political environment, which was one openly challenged by governmental messages about multiculturalism.

While the aim for state arts agency partnerships did not eventuate, the idea of developing a national incubator-a centre for research or workshopsnevertheless persisted with subsequent ACMAC members and staff. As part of AMA 2006, staff commissioned a scoping study to determine the demand for a flagship or 'hub' event space to focus national and international attention and critical acclaim, and build on developments in 
artistic practices that explore multicultural Australia. An arts consultant with over 40 years experience, Justin Mcdonnell undertook this study. On this occasion, it was artists in the field who rejected the concept of a 'flagship' event or space on the grounds that it would take scarce resources away from already under-resourced artists:

The practices are considered to be too diverse to be embraced within any one 'flagship' organisation. A multiplicity of hubs that might contribute, in time, to a national focus could be of value. Yet even there, the concept of 'hubs' was felt to be overly mechanistic. Process and pathway were preferred. (Macdonnell n.d., 1)

The respondents saw the 'flagship' approach as too interventionist on the part of the Australia Council and criticised the (assumed) redirection of scant resources that would come at the expense of grants to NESB artists.

Another attempt to cohere practice and theory around the arts in a multicultural Australia was with the reinvigorated Casula Powerhouse Arts Centre launched in early 2008. The opening exhibition, Australian, reimagined Casula as an international centre for cultural diversity in the arts:

Australian projects an Australia that is beyond the horizon, an Australia that is shaped by multiple cultural identities, types of knowledge and the social conditions that are transacted at the moment of intersection within the common space of the public sphere. (Tsoutas 2010, 6)

This strong opening statement asked what it is be Australian and the implications of this within the multicultural context of the Liverpool region and beyond. Interestingly, in his scoping study of 2008 regarding the potential for a multicultural arts flagship, Macdonnell (n.d., 11) recommended that the Casula model be adequately resourced to deliver its vision as a 'centre of excellence':

Uniquely at the moment in Australia, Casula Powerhouse seeks to value and contextualize the art within a cultural framework so that is sometimes celebrating art and artistic processes but at the same time wrestling with dilemmas of Australianity beyond the simplistic trope of 'one Australia' and through that seeking new interpretations of our culturally complex society. 
The consultants who reviewed AMA 2000 and the consultant who scoped out options in 2008 for a multicultural flagship provided targeted recommendations, none of which were accepted by the executive leadership of the Australia Council. Casula is an example of a moment in which the Australia Council arguably held the potential traction to support a national flagship, only to flounder at the outset. In 2008 the Casula Powerhouse Board confirmed its new direction and accepted its name change to 'Casula, the International Centre for Contemporary Culture'. The remit of the revamped Casula was to bring local government, the Liverpool area's multicultural population and an international arts focus under the one roof (N. Tsoutas 2015, interview). But, despite Macdonnell's (n.d.) recommendation that the Australia Council support this expanded role that Casula wished to pursue, the proposal did not progress. Tsoutas (2015, interview) argues it was a 'missed opportunity to reinscribe the culture that we live in'.

Tsoutas's vision 'to reinscribe the culture that we live in' can lead to a productive result when cultures interact expressively. To 'reinscribe' means rewriting and re-presenting our cultural artefacts as:

Diverse and syncretic. It takes multiple forms of expertise and brings them down to size. Individuals, including scientists [read artists], politicians, and activists, apply their eclectic perspectives in forming projects of nature [read art] making. We might begin by identifying distinctive confluences of knowledge, as well as the nodes of practice and discourse informed by these confluences. (Tsing 2005, 113)

In the process of locating and utilising 'confluences', leaders emerge who may have the capacity to generate traction for change.

\section{International Policy Leadership Discourse}

The last international event to profile the arts in a multicultural Australia was co-hosted by the Australian and British councils in March 2008. Making Creative Cities: The Value of Cultural Diversity in the Arts included presentations by Keith Khan, then head of culture for the London 2012 Olympic and Paralympic Games, Professor Marcia Langton and several former members of ACMAC (British Council 2008). ACMAC had been dismantled by this stage but the AMA policy was still in place. The British Council demonstrated its desire for transformational 
leadership regarding art and cultural difference in the Asia-Pacific region in its approach to the Australia Council on this issue. In turn, the Australia Council provided relational leadership by activating its networks of speakers and artists for the event.

The event brought together Australian and British artists whose work explores cultural difference and workshopped issues with artists, cultural practitioners and academics. Three themes were explored: ideas of different types of leadership, albeit undefined; support for creative production; and participation in creative cities. The theme of 'good leadership is not about one model' identified the need to move from a focus on individuals to the capacities of whole communities; to embed diverse groups and young people in decision-making processes rather than asking the occasional 'opinion'; to identify intercultural innovators; and to expand support beyond managerial leadership into 'intercultural, intellectual community, teaching and creative leadership' (British Council 2008, 7). Each of these criteria gesture towards the generic idea of leadership. However, as the arguments in this chapter show, different leadership is needed for different points of the policy cycle and the types of leadership depend on one's position in the arts sector.

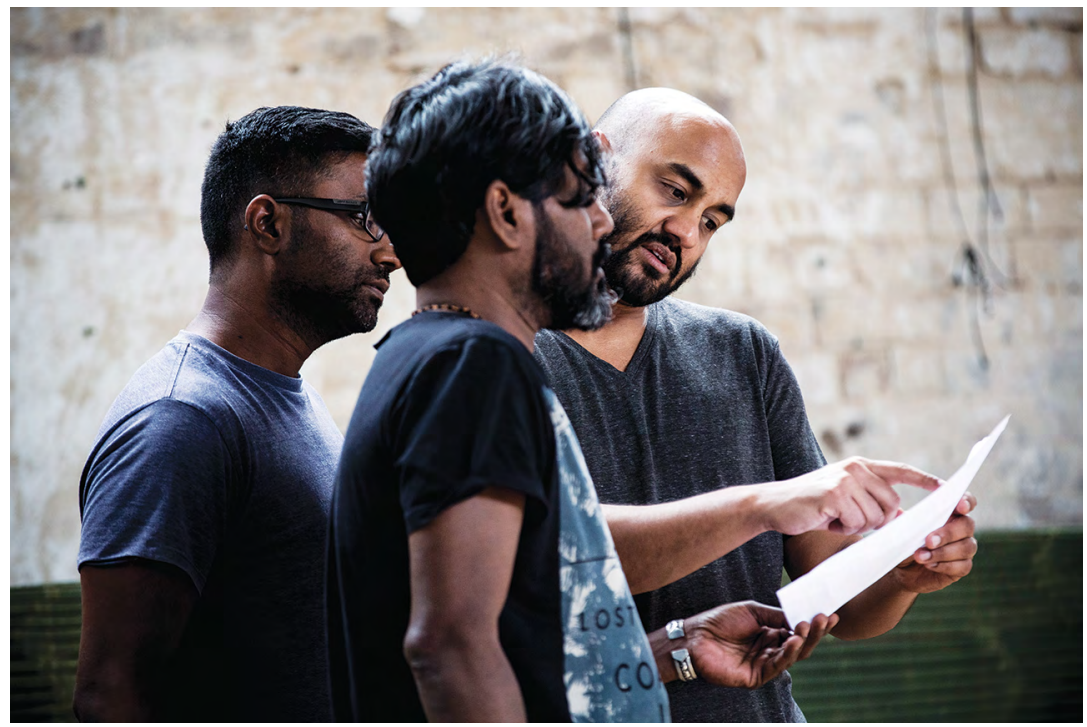

Image 20: Counting and Cracking, Belvoir Street Theatre, 2019

Photographer: @ Brett Boardman 


\section{The Current Role of External Advisers}

Opportunities for NESB artists to become 'embedded' at the Australia Council have since declined. Further, as I have argued, structured instances for professional development, such as developing the skills required for institutional leadership as external advisers, have also reduced in number. Artist, practitioner and CuriousWorks Director (until 2018) Shakthidharan (2015, interview) (see Image 20) notes that he is often asked to provide his 'opinion', but that he is often dissatisfied with the lack of results:

We need to acknowledge corporate history, research what worked well in the past. Pay all the organisations who have been working from a lived experience at grassroots level for a long time to have an action-focused program. We get invited to where everyone talks about all their great ideas and nothing happens. It's like we're on this treadmill of issues that come up every two or three years. What are these things we talk at? And then the talks disappear, with no objective result. At a [recent Community Partnerships Key Producers] roundtable we asked Australia Council to come up with a concrete plan to match diversity on screen and stage within the next 10 years. Not how we'd 'like' to, but how we 'will', starting today. You say these things, but then it disappears.

This interview excerpt details the absence of traction by 'participating peers' in an arts funding institution that no longer seeks consistent advice from multicultural experts in the arts. It is a tactic to casualise expertise that gives the appearance of 'consultation'. The lack of traction stems from the inference that the issues are the responsibility of organisations previously known as 'Key Producers' that had four-year contracts with the Australia Council Community Partnerships Board.

By querying 'what are these things we talk at?', Shakthidharan identifies a lack of clarity regarding the role and direction of leadership. The Key Producers were expected to be leaders in the community arts sector but were not in a position to lead or effect systemic change within the Australia Council. The Australia Council did not provide them with sufficient resources or entry into the world of the major Australian art centres; nevertheless, it was expected that intransigent issues such as a lack of diversity across narrative and performance arts could be, if not solved, managed by financially vulnerable community arts organisations. The Australia Council demonstrates the appearance of interest by 
occasionally bringing arts sector positional leaders together, but appears slow to utilise their input or produce an accountable action plan, thereby reducing trust and the likelihood of traction.

\section{Conclusion}

ACMAC demonstrated positional and transformational leadership when it engaged with critical thinkers around issues of cultural difference. The committee demonstrated this in a number of directions: it led through its position at the Australia Council and through its direct engagement with critical discourse; it showed relational leadership for the arts sector and council staff by providing opportunities to network and engage in critical discussions of cultural difference; and it aimed for transformational leadership by utilising international expertise to unravel some of the complex issues the committee faced, including these results in recommendations to the Australia Council.

Institutional leadership for the arts in a multicultural Australia could be demonstrated by consolidating earlier policy achievements and continuing to identify current issues and the manner in which they will be addressed. I have shown the reluctance on the part of the Australia Council to refresh and develop their direction for the arts in a multicultural Australia, the importance of which is underlined by Klika (2015, interview), a former board member of two national institutions:

The ABC [and] the Australia Council should show that leadership.

Diversity is an evolving beast, and we should be encouraging the evolution, not encouraging the arrestment of multiculturalism. So yes, I think there's plenty of room for leadership at the institutional level.

Although leadership is a familiar term in the arts, it is often used without qualification, which lends it a rhetorical quality that verges on the meaningless. Hewison and Holden (2011) provide a road map of leadership styles that can be included in a 'tool kit' but do not approach the issues of leading for diversity in the arts. I have also elaborated on several types of leadership for the arts in a multicultural Australia as demonstrated through interactions within the institutional frame of the Australia Council. 
Transformational leadership may be more appropriate for those who hold positional leadership at the executive and board level. This includes the more familiar type of personality-dependent, charismatic leadership found in the arts, but runs a high risk of delivering only short-term changes based on the leaders' length of tenure. Distributed leadership was demonstrated by ACMAC, as it enabled members' lead roles to be shared according to the skills of the group and to take into account its fluid cross-cultural and multi-artform membership. Relational leaders enable a vision and create trust in its delivery (Hewison and Holden 2011, 31). This chapter has highlighted the value of relational leadership that places the leader (e.g. previous chairs, some members of ACMAC and staff) in a more central position of developing the necessary relationships to enable others to take on the responsibility for change, thereby generating a longer legacy.

I argue that several leadership characteristics are present at the interface of the NESB artist and the institution. The NESB artist's role is one in which creative leadership capabilities become relevant for institutional leadership capacity. I have shown that the Australia Council's current model of drafting in expert peers on art and multiculturalism on an as-needed basis requires these peers to be experienced, articulate, knowledgeable and bold about supporting creative production and content by NESB artists. The decision to terminate $\mathrm{ACMAC}$ has left a knowledge and experience vacuum within Australia Council processes that is unlikely to be filled. Additionally, the current approach of short-term peer appointments appears inadequate as a 'training ground' for NESB artists to develop the range of characteristics needed to be effective multicultural arts advocates within institutional environments. This process does not develop longitudinal comprehension of the arts sector and, therefore, reduces the capacity within the arts sector for long-term informed policy input.

The advocacy work of Diversity Arts Australia (DARTS), the small organisation with a national diversity remit that replaced the kultour multicultural arts touring network, brings NESB artists together in different parts of Australia to stimulate a discourse of diversity that has been absent for several years. Regardless of the extent of external pressure that DARTS may exert on the Australia Council, it is unlikely to equal the internal traction of an institution-appointed advisory group, because DARTS cannot hold institutional positional influence. 
The Australia Council published two statements in 2018 to address inequity in the arts. The first announced a target of 14 per cent grant expenditure on CALD; however, the council is yet to publish specific strategies on how it aims to achieve this goal. Broadly directed across areas of social diversity in the CEF, the second statement provides additional funds to the major performing companies to develop CEFfocused projects. Shakthidharan expressed disappointment that those funds would not flow to the S2M sector, which has practical experience of working with artists of diverse backgrounds and is able to extract high value from small budgets. These two initiatives may go some way to address immediate symptoms of inequitable use of resources, but may not be adequate to produce the systemic changes that the multicultural arts sector wants to see (Castagna 2017).

The issue of adequacy brings into question whether the 2018 version of CEF is an effective mechanism for generating change for the arts in a multicultural Australia. The Australia Council continues to demonstrate its reluctance. As Migliorino (2015, interview) observes, positional leaders within the Australia Council need to agree on the principles needed to focus the institution's long-term attention towards cultural difference. This level of vision and commitment is yet to become apparent, and is further hindered by a lack of internal 'diversity champions' (i.e. champions who represent each diversity area of the CEF) in dedicated roles. This internal staff role may be theoretically viable; however, if it is as an 'add-on' to substantive or prime staff roles, the potential for institutional leadership is dissipated.

One result of this institutional reluctance to engage with a multicultural society is that artistic activity continues to be produced in small, almost boutique scenarios. The next chapter turns to the leadership role of the NESB artist when partnering with major and mid-tier arts organisations on their own terms to show how multicultural creative practice pushes into greater circulation, thereby amplifying the current multicultural arts milieu. 
This text is taken from Creative Frictions: Arts Leadership, Policy and Practice in Multicultural Australia, by Cecelia Cmielewski, published 2021 by ANU Press, The Australian National University, Canberra, Australia.

doi.org/10.22459/CF.2021.05 